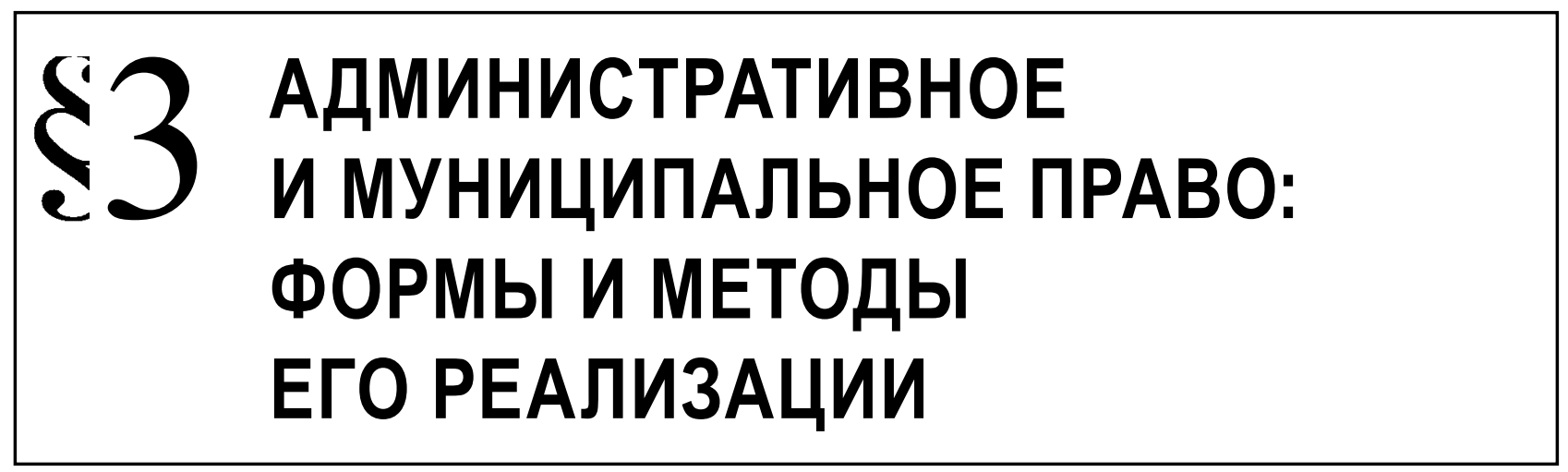

Военкова Н.П.

\title{
АКТУАЛЬНЫЕ ПРОБЛЕМЫ ОБЪЕДИНЕНИЯ КОНТРОЛЬНО-НАДЗОРНЫХ ОРГАНОВ
}

Аннотация. Предметом исследования являются проблемы правового и организационного характера, связанные с административно-правовым регулированием деятельности контрольно-надзорных органов. Статья посвящена актуальной в настоящее время ситуации, связанной с объединением как федеральных, так и региональных органов исполнительной власти. Автором рассмотрены основные причины объединения двух контрольно-надзорных органа - Федеральной антимонопольной службы и Федеральной службы по тарифам, а также проблемы, которые могут возникнуть на практике в связи с их слиянием. Кроме того, рассмотрены проблемы, которые могут возникнуть у региональных контрольных органов при организации плановых проверок начиная с 2016 года, после объединения отдельных органов исполнительной власти субъектов Российской Федерации в единый государственный орган. Методологическую основу статьи составили современные достижения теории познания. В процессе исследования применялись общенаучные и частнонаучные методы познания. Общенаучные методы (системный метод, анализ, синтез, аналогия, наблюдение, моделирование, сравнение), позволили выявить основные тенденции и закономерности развития изучаемого предмета. Частнонаучные методы (формально-юридический, сравнительно-правовой, системно-структурный) дали возможность выделить, описать и воспроизвести исследуемые явления, сопоставить их с целью выявления сходства и различия. Особым вкладом автора в исследовании темы объединения федеральных контрольно-надзорных органов является рассуждение о целесообразности передаче Министерству экономического развития Российской Федерации полномочий Федеральной антимонопольной службы по нормативно-правовому регулированию. Также автор делает вывод о необходимости приведения к единообразию контрольно-надзорных органов субъектов Российской Федерации на примере Главного контрольного управления Хабаровского края.

Ключевые слова: государственный контроль (надзор), организация проверок, проведение проверок, оптимизация бюджетных средств, региональный контроль (надзор), государственное управление, антимонопольное регулирование, антимонопольный орган, нормативно-правовое регулирование, лицензионный контроль. Abstract. The research subject is the range of legal and organizational problems of administrative and legal regulation of the work of regulatory and supervisory authorities. The paper considers the current situation of unification of federal and local executive authority bodies. The author considers the main reasons for unification of the two regulatory and supervisory agencies - the Federal Antimonopoly Service and the Federal Tariffs Service, and the problems which can appear in practice in the process of their unification. The paper studies the problems which regional supervisory authorities can face when organizing routine inspection beginning from 2016 after the unification of particular executive authority bodies in the territorial subjects of the Russian Federation into a single state body. The research methodology comprises the recent achievements in epistemology. The author applies general scientific methods, including the system method, analysis, synthesis, analogy, observation, modeling, and comparison, which help to reveal the main development tendencies and patterns of the subject in question. The specific scientific methods, including the formal-logical, comparative-legal, and system-structural, help to reveal, describe, and reproduce the studied phenomena, and to compare them on order to reveal the similarities and differences. The author discusses the reasonability of transferring the responsibilities of the Federal Antimonopoly Service of the Russian Federation in the sphere of legal regulation to the Ministry of Economic Development. The author concludes about the necessity to unify regulatory and supervisory authorities of territorial subjects of the Russian Federation using the example of the General Regulatory Office of Khabarovsk region.

Key words: licensing supervision, normative and legal regulation, antimonopoly authority, antimonopoly regulation, public management, regional control (supervision), budget optimization, carrying out of inspections, organization of inspections, state control (supervision). 
$\mathrm{B}$ настоящее время в России остро возникла проблема минимизации расходов на содержание государственного аппарата. Полагаем, что решением данной проблемы может являться, в том числе сокращение числа контролирующих органов.

Так, некоторые изменения уже происходят на федеральном уровне исполнительной власти. В частности, в целях совершенствования государственного управления и контроля в сфере антимонопольного и тарифного регулирования, оптимизации структуры федеральных органов исполнительной власти 21 июля 2015 года издан Указ Президента Российской Федерации № 373 об упразднении Федеральной службы по тарифам и передаче ее полномочий Федеральной антимонопольной службе [4].

При этом необходимо отметить, что указанные федеральные органы исполнительной власти подчиняются Правительству Российской Федерации. Вместе с тем, в соответствии со статьей 112 Конституции Российской Федерации Президент Российской Федерации устанавливает систему и структуру федеральных органов исполнительной власти по предложению Председателя Правительства Российской Федерации [1].

Для того, чтобы понять почему были выбраны именно эти два государственных органа исполнительной власти необходимо кратко рассмотреть историю создания и развития указанных органов.

До 1990 года государственное ценовое регулирование на продукцию отрасли «Электроэнергетика» утверждалось Госкомцен СССР. При этом, антимонопольное регулирование в Советский период не осуществлялось.

В 1990 году для проведения государственной политики по развитию товарных рынков и конкуренции, ограничению монополистической деятельности и пресечению недобросовестной конкуренции в составе Совета Министров РСФСР образован Государственный комитет РСФСР по антимонопольной политике и поддержке новых экономических структур. Вскоре после создания антимонопольного комитета принят Закон РСФСР от 22 марта 1991 г. № 948-1 «0 конкуренции и ограничении монополистической деятельности на товарных рынках» [5].

В это же время полномочия по установлению уровней тарифов передавался Федеральной, а также региональным энергетическим комиссиям, образуемым в зоне действия каждого производственного объединения энергетики и электрификации. При этом работа по организации и внедрению государственного регулирования тарифов на электрическую энергию возлагалась на Госкомцен СССР.

Позднее распоряжением Правительства Российской Федерации от 16 марта 1992 г. № 493-р создана Федеральная энергетическая комиссия по рассмотрению вопросов, связанных с формированием тарифов на электрическую и тепловую энергию. При этом организационно-техническое обеспечение деятельности указанной комиссии было возложено на Министерство экономики Российской Федерации [12].

Указом Президента Российской Федерации от 29 ноября 1995 г. № 1194 «0 Федеральной энергетической комиссии Российской Федерации» образована Федеральная энергетическая комиссия Российской Федерации (ФЭК России), которая являлась федеральным органом исполнительной власти, осуществляющим в соответствии с Федеральным законом от 17 августа 1995 г. № 147-Ф3 «0 естественных монополиях» (далее - Федеральный закон «0 естественных монополиях») регулирование деятельности субъектов естественных монополий в топливно-энергетическом комплексе, а также государственное регулирование тарифов на электрическую и тепловую энергию в соответствии с Федеральным законом от 14 апреля 1995 г. № 41-Ф3 «0 государственном регулировании тарифов на электрическую и тепловую энергию в Российской Федерации» [26].

Указом Президента Российской Федерации от 22 сентября 1998 г. № 1142 «0 структуре федеральных органов исполнительной власти» упразднены ряд комитетов и служб, осуществляющих антимонопольное регулирование, в частности, Государственный антимонопольный комитет Российской Федерации, Федеральная служба России по регулированию естественных монополий в области связи, Федеральная служба России по регулированию естественных монополий на транспорте. На их месте образовано Министерство Российской Федерации по антимонопольной политике и поддержке предпринимательства (МАП России) [3].

В 2004 году произошли кардинальные изменения в структуре федеральных органов исполнительной власти, большинство из которых осуществляют свою деятельность по настоящее время. Так, МАП России упразднено, а его полномочия переданы другим ведомствам. Принадлежавшие МАП России функции антимонопольного органа, в том числе контроль за деятельностью естественных монополий и за соблюдением законодательства о рекламе перешли к вновь образованной Федеральной антимонопольной службе (ФАС России). Кроме того, создана Федеральная служба по тарифам (ФСТ России), которой были переданы функции МАП России в части регулирования тарифов на услуги общедоступной электрической и почтовой связи, а также функции Минэкономразвития России по регулированию ценовых составляющих государственного оборонного заказа, производ- 


\section{Административное и муниципальное право 5 (101) • 2016}

ства ядерного топлива, сжиженного бытового газа, ценообразования в отношении лекарственных средств, зерновых товарно-закупочных интервенций и целому ряду других позиций.

Таким образом, из истории создания и развития двух органов государственной власти - ФСТ России и ФАС России, просматривается тесное переплетение осуществляемых ими полномочий и функций.

Отдельно следует обратить внимание на одно из контрольных мероприятий Счетной палаты Российской Федерации, которое в соответствии с планом ее работы в 2012 году было направлено в сторону ФАС России. Счетная палата Российской Федерации оценивала деятельность антимонопольного органа с точки зрения эффективности его работы и использования бюджетных средств. В область внимания Счетной палаты Российской Федерации попали нормативно-правовая и методологическая базы федеральной службы, бюджетное финансирование и деятельность ФАС России по контролю в сфере естественных монополий.

Основное замечание Счетной палаты Российской Федерации заключалось в отсутствии согласованности между ФСТ России и ФАС России в вопросе регулирования естественных монополий. По мнению Счетной палаты Российской Федерации, государственный контроль за соблюдением законодательства в сфере естественных монополий регламентируется Федеральным законом «0 естественных монополиях». То есть, субъекты естественных монополий подконтрольны двум федеральным органам исполнительной власти: ФАС России - в рамках антимонопольного регулирования и контроля, и ФСТ России - в части ценового регулирования и контроля [24].

К полномочиям ФАС России, в частности, относится ведение Реестра хозяйствующих субъектов, имеющих долю на рынке определенного товара в размере более чем 35 процентов или занимающих доминирующее положение на рынке определенного товара, если в отношении такого рынка федеральными законами установлены случаи признания доминирующим положения хозяйствующих субъектов (далее - Реестр ФАС России). ФСТ России ведет и формирует Реестр субъектов естественных монополий, в отношении которых осуществляется государственное регулирование и контроль (далее - Реестр ФСТ России).

При этом, в ходе аудиторской проверки было выявлено, что далеко не все субъекты естественных монополий из Реестра ФСТ России включены в Реестр ФАС России. И наоборот, не все организации, фактически осуществляющие естественномонопольные виды деятельности и включенные в Реестр ФАС России, включены в Реестр ФСТ России.
То есть, между контрольными органами, по существу, отсутствует четкий механизм взаимодействия и координации.

Кроме того, проверка показала, что контрольные полномочия, предусмотренные Федеральным законом «0 естественных монополиях», осуществляются ФАС России и ее территориальными органами в форме последующего контроля при получении обращения (жалобы), а не как регулярная планомерная деятельность. Доля плановых проверок в ФАС России незначительна и в основном проводилась в области электроэнергетики. Антимонопольный орган не имеет методики планирования проведения проверок на год и порядка включения в Ежегодный план проведения плановых проверок юридических лиц (их филиалов, представительств, обособленных структурных подразделений) и индивидуальных предпринимателей (далее - план проверок) субъектов естественных монополий, что в свою очередь снижает качество контроля и надзора [24].

Таким образом, оптимизация деятельности контрольно-надзорных органов, в частности, объединение ФАС России и ФСТ России, в период экономической нестабильности, несомненно, рационально.

В ходе такого объединения исключены дублирующие контрольно-надзорные функции в отношении субъектов естественной монополии, а также региональных энергетических комиссий.

Распределение полномочий в части осуществления нормативно-правового регулирования и контрольной деятельности как на федеральном, так и на региональном уровнях в отношении региональных энергетических комиссий до объединения ФАС России и ФСТ России и после слияния указано в Приложении (Рисунок № 1).

Распределение полномочий в части осуществления нормативно-правового регулирования и контрольной деятельности как на федеральном, так и на региональном уровнях в отношении субъектов естественной монополии до объединения ФАС России и ФСТ России и после слияния указано в Приложении (Рисунок № 2).

Вместе с тем, необходимо обратить внимание на то, что в результате такого объединения могут «пострадать» конкуренция, а самое главное - потребители услуг субъектов естественных монополий, физические и юридические лица.

Так, ранее ФСТ России не только устанавливало правила для субъектов естественных монополий, а также региональных энергетических комиссий, но и проверяло их соблюдение. При этом ФАС России имело возможность провести проверку законности и обоснованности установления ФСТ России цен (тарифов) на услуги субъектов естественной монополии в соответствии с Федеральным законом от 26 
июля 2006 г. № 135-Ф3 «0 защите конкуренции», а также проверку соблюдения законодательства Российской Федерации в пределах компетенции субъектами естественных монополий. Аналогичными полномочиями были наделены территориальные антимонопольные органы в отношении региональных энергетических комиссий и субъектов естественной монополии $[8,13]$.

Сейчас же, после объединения с ФСТ России и осуществлении полномочий в сфере государственного регулирования цен (тарифов) на товары (услуги), проверять «себя», «свою работу» ФАС России не будет.

Таким образом, остается открытым вопрос о том, какой орган государственной власти будет проверять соблюдение ФАС России установленного порядка ценообразования в сфере деятельности естественных монополий.

Выше рассмотрен пример оптимизации деятельности контрольно-надзорных органов на федеральном уровне.

Но на уровне субъектов Российской Федерации такие изменения пока происходят не часто. Например, Правительством Хабаровского края принято постановление от 16 октября 2012 г. № 371-пр о создании Главного контрольного управления, в полномочия которого входят региональный государственный экологический надзор; государственный контроль за оборотом древесины; лицензионный контроль за соблюдением лицензионных требований и условий при осуществлении заготовки, хранения, переработки и реализации лома цветных и черных металлов; региональный государственный надзор в области племенного животноводства; надзор и контроль за приемом на работу инвалидов в пределах установленной квоты с правом проведения проверок, выдачи обязательных для исполнения предписаний и составления протоколов; региональный государственный контроль за осуществлением перевозок пассажиров и багажа легковым такси [15].

Таким образом, созданное Главное контрольное управление Правительства Хабаровского края, по сути, заменило ряд органов государственного контроля (надзора) Хабаровского края, таких как: Министерство природных ресурсов, Министерство сельского хозяйства и продовольствия, Министерство промышленности и транспорта, Комитет по труду и занятости населения.

Необходимо отметить, что в устройстве исполнительной власти имеет место процесс перераспределения компетенции между органами исполнительной власти, и в этом случае действует механизм централизации, децентрализации, в том числе делегирования (передачи части полномочий), что является прямым продолжением раз- граничения полномочий в сфере исполнительной власти, определенной Конституцией Российской Федерации [20].

Такое объединение, как и вышеописанное объединение ФАС России и ФСТ России, несомненно, позволяет снизить издержки государства на содержание аппарата чиновников.

Умелое использование разных способов перераспределения компетенции не должно подрывать стабильность и эффективность выполнения публичных функций, обеспечивая необходимую гибкость [21].

Вместе с тем следует отметить, что на практике при осуществлении такого государственного контроля (надзора) могут возникнуть следующие проблемы.

Так, Федеральным законом от 14 октября 2014 г. № 307-Ф3 «0 внесении изменений в Кодекс Российской Федерации об административных правонарушениях и отдельные законодательные акты Российской Федерации и о признании утратившими силу отдельных положений законодательных актов Российской Федерации в связи с уточнением полномочий государственных органов и муниципальных органов в части осуществления государственного контроля (надзора) и муниципального контроля», вступившем в силу 15 ноября 2014 г., внесены изменения в Федеральный закон от 26 декабря 2008 г. № 294-Ф3 «0 защите прав юридических лиц и индивидуальных предпринимателей при осуществлении государственного контроля (надзора) и муниципального контроля» (далее Федеральный закон № 294-ФЗ).

В соответствии с частью 1 статьи 9 Федерального закона № 294-ФЗ предметом плановой проверки является соблюдение юридическим лицом, индивидуальным предпринимателем в процессе осуществления деятельности совокупности предъявляемых обязательных требований и требований, установленных муниципальными правовыми актами.

Пункт 6 статьи 2 Федерального закона № 294Ф3 определяет проверку, как совокупность проводимых органом государственного контроля (над3ора) или органом муниципального контроля в отношении юридического лица, индивидуального предпринимателя мероприятий по контролю для оценки соответствия осуществляемых ими деятельности или действий (бездействия), производимых и реализуемых ими товаров (выполняемых работ, предоставляемых услуг) обязательным требованиям и требованиям, установленным муниципальными правовыми актами [9].

Исходя из изложенного, уполномоченный орган государственного контроля (надзора) или орган муниципального контроля проводит проверку 


\section{Административное и муниципальное право 5 (101) • 2016}

соблюдения юридическим лицом, индивидуальным предпринимателем всей совокупности предъявляемых обязательных требований и требований, установленных муниципальными правовыми актами, и подлежащих проверке конкретным уполномоченным органом контроля (надзора).

Таким образом, Главное контрольное управление Правительства Хабаровского края вправе проводить плановую проверку по совокупности видов контрольно-надзорной деятельности, установленных постановлением Правительства Хабаровского края от 16 октября 2012 г. № 371-пр, и указанных выше.

Необходимо отметить, что такие изменения в Федеральный закон № 294-ФЗ вступили в силу после подготовки контрольно-надзорными органами планов проверок на 2015 год в соответствии с Правилами подготовки органами государственного контроля (надзора) и органами муниципального контроля ежегодных планов проведения плановых проверок юридических лиц и индивидуальных предпринимателей, утвержденными постановлением Правительства Российской Федерации от 30 июня 2010 г. № 489, и, следовательно, начинают действовать при организации плановых проверок на 2016 год.

То есть, если Главное контрольное управление Правительства Хабаровского края в 2015 году провело плановую проверку юридического лица и индивидуального предпринимателя на предмет соблюдения ими лицензионных требований при осуществлении заготовки, хранения, переработки и реализации лома цветных и черных металлов, то в план проверок в 2016 году включить данное лицо на предмет соблюдения им требований, например, за осуществлением перевозок пассажиров и багажа легковым такси, будет невозможно.

Таким образом, начиная с 2016 года проведение плановой проверки в отношении юридических лиц и индивидуальных предпринимателей по конкретному виду контроля (надзора), без учета времени, прошедшего с момента окончания последней плановой проверки, проведенной данным государственным органом по иному виду контроля (надзора), будет являться нарушением законодательства Российской Федерации.

Установленный законодателем подход проведения такой комплексной плановой проверки юридического лица или индивидуального предпринимателя в рамках Федерального законом № 294-ФЗ имеет как сторонников и противников.

Так, если хозяйствующий субъект имеет в своем распоряжении, например, отдел бухгалтерии и юридический отдел, то ему, конечно, будет удобнее принять комплексную проверку одномоментно, а не постепенно в течение года.

Но, если у хозяйствующего субъекта только один бухгалтер и нет ни юриста, ни других специ- алистов, то комплексная проверка будет для него обременением, поскольку потребует немалых сил на подготовку в короткие сроки материалов и ответов по каждой проверке на запросы контролирующего органа.

Кроме того, в случае выявления нарушения обязательных требований, наложение параллельно даже двух административных штрафов проверяемое лицо может не «потянуть» в финансовом плане.

Также проблема в правоприменении может возникнуть и в установлении отсчета сроков планирования проверок.

Так, по общему правилу, плановые проверки проводятся не чаще чем один раз в три года (часть 2 статьи 9 Федерального закона № 294-Ф3).

Однако, например, в соответствии с пунктом 1 части 9 статьи 19 Федерального закона от 4 мая 2011 г. № 99-Ф3 «О лицензировании отдельных видов деятельности» основанием для включения плановой проверки лицензиата в план проверок является истечение одного года со дня принятия решения о предоставлении лицензии или переоформлении лицензии [10].

В связи с этим остается не решенным вопрос, как Главному контрольному управлению Правительства Хабаровского края планировать проведение плановой проверки юридического лица или индивидуального предпринимателя в 2016 году на предмет соблюдения им совокупности обязательных требований, если в 2015 году был проведен лицензионный контроль указанного лица.

Решением данной проблемы может быть следующее.

Министерство экономического развития Российской Федерации во исполнение поручения Президента Российской Федерации разработало и внесло в Правительство Российской Федерации проект федерального закона о государственном и муниципальном контроле и надзоре в Российской Федерации (далее - законопроект) [17].

Ключевым отличием новой модели регулирования контроля (надзора) от действующего порядка также является создание сквозного цикла прогнозирования, планирования и анализа результатов контрольно-надзорных мероприятий на основе оценки потенциальной опасности видов экономической деятельности и подконтрольных (поднадзорных) субъектов, а также оценки вероятности осуществления данных угроз.

Также в законопроекте предлагается установить особенности организации контрольно-надзорных мероприятий в зависимости от предмета и объема потенциальной угрозы, вероятности ее наступления и истории правонарушений подконтрольных (поднадзорных) субъектов. 
Таким образом, в случае принятия законопроекта в ближайшее время, можно рекомендовать остальным субъектам Российской Федерации начинать внедрять практику объединения (слияния) контрольно-надзорных органов по аналогии с практикой Правительства Хабаровского края. Это целесообразно сделать также в целях обеспечения общефедеральных государственных интересов. Система государственного контроля Российской Федерации должна соответствовать единой системе исполнительной власти.

Анализируя вышеизложенное, можно сделать вывод о том, что полномочия контрольно-надзорных органов имеют схожие функции и в некоторых моментах, по существу, дублируются.

В связи с этим целесообразно пересмотреть все полномочия, осуществляемые в настоящее время органами государственной власти как на федеральном, так и на региональном и муниципальном уровнях, с целью их возможной оптимизации и сокращения.

0 необходимости осуществления систематизации контрольно-надзорных органов для того, чтобы иметь представление об объемах работы указанных органов всех уровней неоднократно высказывались учеными-административистами [23].

Отмечаем, что основными чертами (функциями), определяющими правовое положение федеральных органов исполнительной власти, для федеральных министерств является осуществление нормативно-правового регулирования в установленной сфере деятельности, а для федеральных служб - осуществление контроля и надзора в установленной сфере деятельности.

В связи с этим полагаем, что нормотворческие полномочия ФАС России целесообразно передать
Министерству экономического развития Российской Федерации, как это было уже в истории Федеральной службы по тарифам, иначе, на практике, возникает конфликт интересов: служба разрабатывает проекты нормативных правовых актов, которые потом сама и применяет.

В качестве примера можно выделить следующее. В соответствии с Положением о Министерстве экономического развития Российской Федерации, утвержденным постановлением Правительства Российской Федерации от 5 июня 2008 г. № 437, Минэкономразвития России является федеральным органом исполнительной власти, осуществляющим функции по выработке государственной политики и нормативно-правовому регулированию в сфере осуществления закупок товаров, работ, услуг для обеспечения государственных и муниципальных нужд. Однако, Федеральная антимонопольная служба является уполномоченным федеральным органом исполнительной власти, осуществляющим функции по контролю (надзору) в сфере государственного оборонного заказа, в сфере закупок товаров, работ, услуг для обеспечения государственных и муниципальных нужд (Положение о Федеральной антимонопольной службе, утвержденное постановлением Правительства Российской Федерации от 30 июня 2004 г. № 331) [13-14].

Кроме того, передача Министерству экономического развития Российской Федерации функции по принятию нормативных правовых актов, относящихся в настоящее время к сфере ведения Федеральной антимонопольной службы, может решить проблему слияния ФАС России и ФСТ России, описанную выше, и привести к наилучшим результатам для общества в целом.

Приложение

Рисунок № 1

Распределение полномочий ФАС России и ФСТ России в отношении региональных энергетических комиссий

До объединения

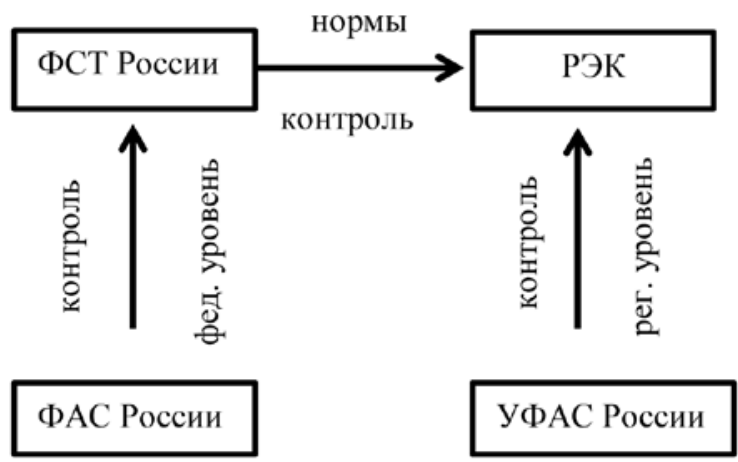

После объединения

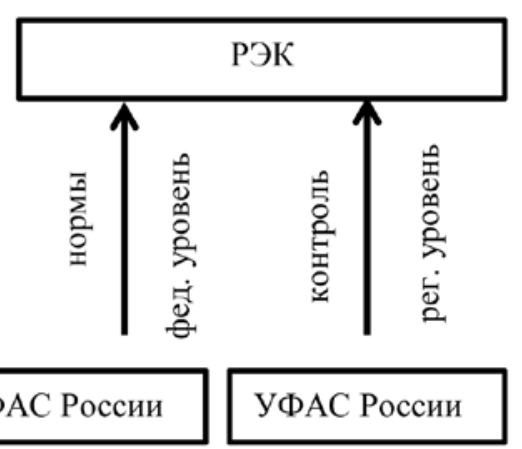


Рисунок № 2

Распределение полномочий ФАС России и ФСТ России

в отношении субъектов естественной монополии

До объединения

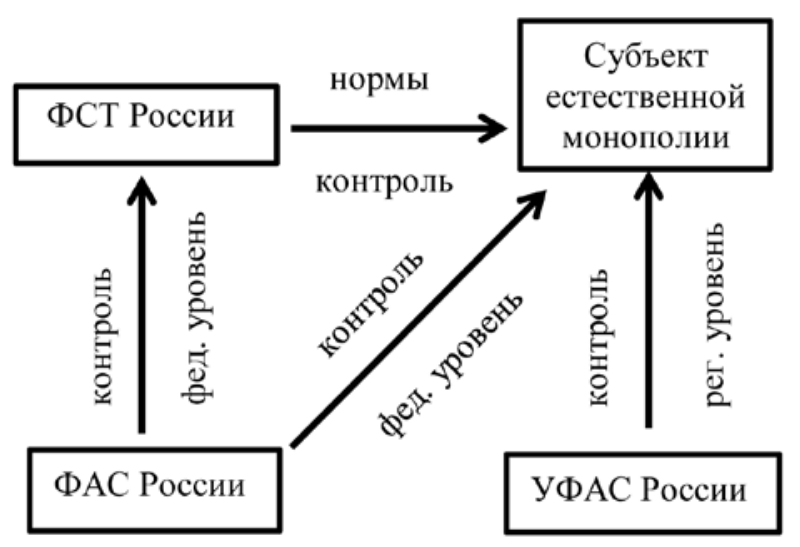

После объединения

Субъект естественной монополии

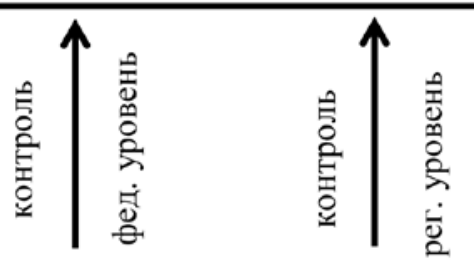

ФАС России

УФАС России

\section{Библиография:}

1. Конституция Российской Федерации.

2. Указ Президента Российской Федерации от 29 ноября 1995 г. № 1194 "О Федеральной энергетической комиссии Российской Федерации".

3. Указ Президента Российской Федерации от 22 сентября 1998 г. № 1142 "О структуре федеральных органов исполнительной власти".

4. Указ Президента Российской Федерации от 21 июля 2015 г. № 373 "О некоторых вопросах государственного управления и контроля в сфере антимонопольного и тарифного регулирования".

5. Закон РСФСР от 22 марта 1991 г. № 948-1 "О конкуренции и ограничении монополистической деятельности на товарных рынках".

6. Федеральный закон от 14 апреля 1995 г. № 41-Ф3 "О государственном регулировании тарифов на электрическую и тепловую энергию в Российской Федерации".

7. Федеральный закон от 17 августа 1995 г. № 147-ФЗ "О естественных монополиях".

8. Федеральный закон от 26 июля 2006 г. № 135-ФЗ "О защите конкуренции".

9. Федеральный закон от 26 декабря 2008 г. № 294-Ф3 "О защите прав юридических лиц и индивидуальных предпринимателей при осуществлении государственного контроля (надзора) и муниципального контроля".

10. Федеральный закон от 4 мая 2011 г. № 99-ФЗ "О лицензировании отдельных видов деятельности".

11. Федеральный закон от 14 октября 2014 г. № 307-ФЗ "О внесении изменений в Кодекс Российской Федерации об административных правонарушениях и отдельные законодательные акты Российской Федерации и о признании утратившими силу отдельных положений законодательных актов Российской Федерации в связи с уточнением полномочий государственных органов и муниципальных органов в части осуществления государственного контроля (надзора) и муниципального контроля".

12. Распоряжение Правительства Российской Федерации от 16 марта 1992 г. № 493-р "О создании Федеральной энергетической комиссии по рассмотрению вопросов, связанных с формированием тарифов на электрическую и тепловую энергию".

13. постановление Правительства Российской Федерации от 30 июня 2004 г. № 331 "Об утверждении Положения о Федеральной антимонопольной службе".

14. постановление Правительства Российской Федерации от 5 июня 2008 г. № 437 "Об утверждении Положения о Министерстве экономического развития Российской Федерации".

15. постановление Правительства Хабаровского края от 16 октября 2012 г. № 371-пр "Об утверждении Положения о главном контрольном управлении Правительства Хабаровского края".

16. приказ ФАС России от 23 июля 2015 г. № 649/15 "Об утверждении Положения о территориальном органе Федеральной антимонопольной службы" (Зарегистрирован в Минюсте России 24 августа 2015 г. № 38653).

17. проект федерального закона о государственном и муниципальном контроле и надзоре в Российской Федерации, http://xn----8sbmmlgncfbgqis7m.xn--p1ai./.

18. Алехин А.П., Кармолицкий А.А. Административное право России: учебник для юридических вузов и факультетов. М., Зерцало-М, 2013.

19. Аралбаева Ф.3. и др. Система контрольных органов исполнительной власти на различных уровнях управления. // Вестник Оренбургского государственного университета. 2002. - 5. С. 63-67.

20. Административное право России: учебник / под ред. Н.М. Конина, Ю.Н. Старилова. М., Норма. Инфра-М, 2010, С. 197-198. 
21. Столяров М.В. Компетенция власти. Разграничение предметов ведения и полномочий между Федерацией и ее субъектами в условиях реформирования: учебное пособие. М. Издательство РАГС. 2005. С. 27-28.

22. Попов Л.Л. Административное право Российской Федерации: учебник для бакалавров. М., Юрайт, 2012.

23. Зырянов С.М. К вопросу о координации государственного контроля и надзора // Актуальные проблемы правового обеспечения государственного управления: сборник научных статей. Под ред. В.А. Козбаненко и С.М. Зубарева. М. 2009. С. 53.

24. Счетная палата проверила ФАС // Конкуренция и право. Выпуск № 16, за 16 - 22 апреля 2012 г., http://www. cljournal.ru/vibor/26/.

25. http://www.fas.gov.ru/about/overview/.

26. http://www.fstrf.ru/about/activity/17

27. М.В. Костенников К вопросу о некоторых актуальных проблемах административного права // Право и политика. 2013. - 5. - C. 700 - 707. DOI: 10.7256/1811-9018.2013.05.14.

\section{References (transliterated):}

1. Konstitutsiya Rossiiskoi Federatsii.

2. Ukaz Prezidenta Rossiiskoi Federatsii ot 29 noyabrya 1995 g. № 1194 "O Federal'noi energeticheskoi komissii Rossiiskoi Federatsii".

3. Ukaz Prezidenta Rossiiskoi Federatsii ot 22 sentyabrya 1998 g. № 1142 "O strukture federal'nykh organov ispolnitel'noi vlasti".

4. Ukaz Prezidenta Rossiiskoi Federatsii ot 21 iyulya 2015 g. № 373 "O nekotorykh voprosakh gosudarstvennogo upravleniya i kontrolya $v$ sfere antimonopol'nogo i tarifnogo regulirovaniya".

5. Zakon RSFSR ot 22 marta 1991 g. № 948-1 "O konkurentsii i ogranichenii monopolisticheskoi deyatel'nosti na tovarnykh rynkakh".

6. Federal'nyi zakon ot 14 aprelya 1995 g. № 41-FZ "0 gosudarstvennom regulirovanii tarifov na elektricheskuyu i teplovuyu energiyu v Rossiiskoi Federatsii".

7. $\quad$ Federal'nyi zakon ot 17 avgusta 1995 g. № 147-FZ "O estestvennykh monopoliyakh".

8. Federal'nyi zakon ot 26 iyulya 2006 g. № 135-FZ "0 zashchite konkurentsii".

9. Federal'nyi zakon ot 26 dekabrya $2008 \mathrm{~g}$. № 294-FZ "O zashchite pravyuridicheskikh lits i individual'nykh predprinimatelei pri osushchestvlenii gosudarstvennogo kontrolya (nadzora) i munitsipal'nogo kontrolya".

10. Federal'nyi zakon ot 4 maya 2011 g. № 99-FZ "O litsenzirovanii otdel'nykh vidov deyatel'nosti".

11. Federal'nyi zakon ot 14 oktyabrya 2014 g. № 307-FZ "O vnesenii izmenenii v Kodeks Rossiiskoi Federatsii ob administrativnykh pravonarusheniyakh i otdel'nye zakonodatel'nye akty Rossiiskoi Federatsii i o priznanii utrativshimi silu otdel'nykh polozhenii zakonodatel'nykh aktov Rossiiskoi Federatsii v svyazi s utochneniem polnomochii gosudarstvennykh organov i munitsipal'nykh organov $\mathrm{v}$ chasti osushchestvleniya gosudarstvennogo kontrolya (nadzora) i munitsipal'nogo kontrolya".

12. Rasporyazhenie Pravitel'stva Rossiiskoi Federatsii ot 16 marta 1992 g. № 493-r "O sozdanii Federal'noi energeticheskoi komissii po rassmotreniyu voprosov, svyazannykh s formirovaniem tarifov na elektricheskuyu i teplovuyu energiyu".

13. postanovlenie Pravitel'stva Rossiiskoi Federatsii ot 30 iyunya 2004 g. № 331 "Ob utverzhdenii Polozheniya o Federal'noi antimonopol'noi sluzhbe".

14. postanovlenie Pravitel'stva Rossiiskoi Federatsii ot 5 iyunya 2008 g. № 437 "Ob utverzhdenii Polozheniya o Ministerstve ekonomicheskogo razvitiya Rossiiskoi Federatsii".

15. postanovlenie Pravitel'stva Khabarovskogo kraya ot 16 oktyabrya 2012 g. № 371-pr "Ob utverzhdenii Polozheniya o glavnom kontrol'nom upravlenii Pravitel'stva Khabarovskogo kraya".

16. prikaz FAS Rossii ot 23 iyulya 2015 g. № 649/15 "Ob utverzhdenii Polozheniya o territorial'nom organe Federal'noi antimonopol'noi sluzhby" (Zaregistrirovan v Minyuste Rossii 24 avgusta 2015 g. № 38653).

17. proekt federal'nogo zakona o gosudarstvennom i munitsipal'nom kontrole i nadzore v Rossiiskoi Federatsii, http://xn---8sbmmlgncfbgqis7m.xn--p1ai./.

18. Alekhin A.P., Karmolitskii A.A. Administrativnoe pravo Rossii: uchebnik dlya yuridicheskikh vuzov i fakul'tetov. M., Zertsalo-M, 2013.

19. Aralbaeva F.Z. i dr. Sistema kontrol'nykh organov ispolnitel'noi vlasti na razlichnykh urovnyakh upravleniya. // Vestnik Orenburgskogo gosudarstvennogo universiteta. 2002. - 5. S. 63-67.

20. Administrativnoe pravo Rossii: uchebnik / pod red. N.M. Konina, Yu.N. Starilova. M., Norma. Infra-M, 2010, S. 197-198.

21. Stolyarov M.V. Kompetentsiya vlasti. Razgranichenie predmetov vedeniya i polnomochii mezhdu Federatsiei i ee sub"ektami v usloviyakh reformirovaniya: uchebnoe posobie. M. Izdatel'stvo RAGS. 2005. S. 27-28.

22. Popov L.L. Administrativnoe pravo Rossiiskoi Federatsii: uchebnik dlya bakalavrov. M., Yurait, 2012.

23. Zyryanov S.M.Kvoprosu o koordinatsii gosudarstvennogo kontrolyainadzora // Aktual'nye problemypravovogo obespecheniya gosudarstvennogo upravleniya: sbornik nauchnykh statei. Pod red. V.A. Kozbanenko i S.M. Zubareva. M. 2009. S. 53.

24. Schetnaya palata proverila FAS // Konkurentsiya i pravo. Vypusk № 16, za 16 - 22 aprelya 2012 g., http://www.cljournal. $\mathrm{ru} /$ vibor $/ 26 /$.

25. http://www.fas.gov.ru/about/overview/.

26. http://www.fstrf.ru/about/activity/17

27. M.V. Kostennikov K voprosu o nekotorykh aktual'nykh problemakh administrativnogo prava // Pravo i politika. - 2013. 5. - C. 700 - 707. DOI: 10.7256/1811-9018.2013.05.14. 